\title{
Frailty and Liver resection: where do we stand?
}

\author{
Georgios S. Sioutas ${ }^{1, \#}$, loannis A. Ziogas ${ }^{2, \#}$, Georgios Tsoulfas ${ }^{2}$ \\ 1Department of Medicine, School of Health Sciences, Democritus University of Thrace, Alexandroupolis 68100, Greece. \\ ${ }^{2}$ First Department of Surgery, Papageorgiou University Hospital, Aristotle University of Thessaloniki, Thessaloniki 54622, Greece. \\ \#Authors contributed equally.
}

Correspondence to: Dr. Georgios Tsoulfas, FICS, FACS, Associate Professor of Surgery, First Department of Surgery, Papageorgiou University Hospital, Aristotle University of Thessaloniki, 66 Tsimiski Street, Thessaloniki 54622, Greece. E-mail: tsoulfasg@gmail.com

How to cite this article: Sioutas GS, Ziogas IA, Tsoulfas G. Frailty and Liver resection: where do we stand? Hepatoma Res 2020;6:4. http://dx.doi.org/10.20517/2394-5079.2019.43

Received: 3 Dec 2019 First Decision: 15 Jan 2020 Revised: 22 Jan 2020 Accepted: 10 Feb 2020 Published: 20 Feb 2020

Science Editor: Bruno Nardo Copy Editor: Jing-Wen Zhang Production Editor: Tian Zhang

\begin{abstract}
As the world population is continuously aging, the number of older patients requiring liver surgery is also on the rise. Data have shown that age should not be a limiting factor for liver resection, as it cannot accurately predict postoperative outcomes. Instead, frailty can serve as a more reliable measure of the patient's overall health and functional reserves. Several frailty assessment tools have been implemented for preoperative risk stratification before liver surgery, and higher scores have commonly been associated with postoperative morbidity, mortality, and length of hospital stay. However, no consensus has been reached on the most useful screening tool. Future studies should focus on comparing the currently available assessment tools, constructing a liver resection-specific tool, and assessing the role of frailty assessment tools in preoperative patient optimization.
\end{abstract}

Keywords: Frailty, age, elderly, liver resection, liver surgery, morbidity, morbidity, complications

\section{INTRODUCTION}

Liver resection is the current standard of care for most patients with benign or malignant liver lesions and adequate liver function ${ }^{[1,2]}$. Advances in healthcare have led to a continually increasing life-expectancy, which consequently leads to a higher number of elderly patients ( $>60$ years) being offered liver surgery ${ }^{[2,3]}$. Several studies sought to compare liver resection in younger $v$ s. older surgical candidates and reported varying yet acceptable outcomes in appropriately selected older individuals ${ }^{[2,4-8]}$. In fact, morbidity and mortality rates in patients undergoing liver resection for hepatocellular carcinoma (HCC) seem to range

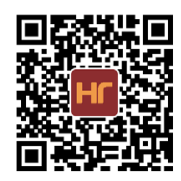


$9 \%-51 \%$ and $0 \%-42.9 \%$, respectively ${ }^{[9]}$. Normal aging is associated with a gradual decline in the function of most organ systems, including the liver. The liver synthetic and metabolic activity, liver volume, and blood flow to the liver seem to be significantly affected in the elderly ${ }^{[10]}$. It is well known that the liver remnant regenerates after liver resection, and the final liver volume after regeneration does not seem to differ between younger and older individuals ${ }^{[9,11]}$. However, this process might be delayed in the elderly due to the liver's decreased proliferative capacity in the early period after the loss of the liver mass ${ }^{[12]}$. Data have shown that liver regeneration after living donor liver transplantation can be delayed in older donors when compared to younger donors ${ }^{[13]}$. These findings indicate that physiological deconditioning and remaining organ function might have a more significant effect on clinical outcomes than the actual chronological age ${ }^{[14,15]}$.

Frailty syndrome is defined as the increased vulnerability to stressors, loss of ability to adapt, and diminished resiliency secondary to an age-related decline in the physiological reserves and function of multiple organ systems ${ }^{[16,17]}$. It is essential to distinguish frailty from "comorbidity" and "disability"; although these three terms overlap to some extent and are often used interchangeably to predict patient outcomes, they represent entirely different entities ${ }^{[18]}$. As described by Feinstein, "comorbidity" is "any distinct additional entity that has existed or may occur during the clinical course of a patient who has the index disease under study" ${ }^{\text {"19] }}$. The term "disability" refers to the abnormal biological functioning or the defect that renders individuals inferior to the "normal" species around them leading to loss of social stability and survival ${ }^{[20]}$. Frailty should also not be considered synonymous to aging ${ }^{[21]}$, but rather an intermediate clinical state between normal and pathological aging ${ }^{[22]}$. Frail patients commonly fail to return to their prior homeostasis after a stressor, resulting in adverse clinical outcomes ${ }^{[23,24]}$. Therefore, the need for developing accurate risk-stratification tools that can potentially identify older patients at risk for postoperative complications is apparent ${ }^{[25]}$.

The aim of the present review is to summarize the impact of age on patient outcomes after liver surgery, describe the available frailty assessment tools, and discuss the impact of frailty on postoperative outcomes in patients undergoing liver resection.

\section{LIVER RESECTION AND AGE}

Several studies sought to investigate the outcomes of liver resection in young $v$ s. old patients. Fong et al. ${ }^{[26]}$ published one of the first studies examining the effect of age on liver surgery. Their study included 133 patients older than 65 years undergoing liver resection for colorectal liver metastases, and they found that age was an independent risk factor for increased risk of morbidity. According to the authors, major hepatic resection may be safely performed and result in favorable functional outcomes on appropriately selected older patients ${ }^{[26]}$. Cho et al. ${ }^{[2]}$ investigated the safety of liver resection in the elderly and reported favorable outcomes in patients $\geq 70$ years. Although most elderly patients were transferred to rehabilitation facilities postoperatively, there was no difference in terms of severe postoperative complications. The authors also performed a literature review and included 14 previous studies; only two $(14.3 \%)^{[27,28]}$ of them reported a statistically significant difference in severe postoperative complications and only two $(14.3 \%)^{[28,29]}$ reported a statistically significant difference in mortality between old and young patients. Additionally, a large single-center study from France showed that age $\geq 75$ years is a risk factor of mortality after liver resection ${ }^{[30]}$, while a multicenter study from the US showed that increasing age is associated with increased postoperative sepsis and overall mortality, but not overall morbidity ${ }^{[31]}$.

As liver resection represents the mainstay of treatment in non-metastatic $\mathrm{HCC}^{[32-34]}$, several studies aimed to investigate the difference in outcomes between young and old HCC patients. Therefore, data have proven the safety and feasibility of liver resection in appropriately selected patients aged not only more than 70 years, but, in some cases, even more than 80 years ${ }^{[35-38]}$. A meta-analysis ${ }^{[39]}$ reported that the morbidity and mortality 


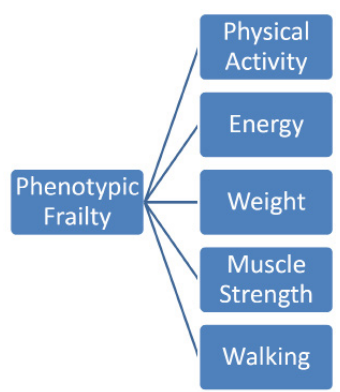

Figure 1. "Physical Frailty Phenotype" model by Fried et al. ${ }^{[14]}$

rates did not differ significantly between older and younger patients undergoing hepatic resection for HCC, while the risk of mortality for younger patients was 2.7 times lower when compared to the elderly for colorectal liver metastases ${ }^{[39]}$. Interestingly, another meta-analysis reported that hepatic resection for liver malignancies is associated with a higher risk of postoperative renal failure, infection, and mortality in older $v s$. younger patients, while the length of stay (LOS) in the hospital, transfusions, and disease-free survival did not differ significantly between the two groups ${ }^{[40]}$. Nevertheless, the considerable variability in patient outcomes after liver resection in the elderly underlines the inability of age alone to predict postoperative outcomes accurately. Instead, factors that reflect the overall health status of the patient, such as frailty, may serve as more accurate predictors of postoperative outcomes. On that grounds, several frailty assessment tools have been developed in order to preoperatively determine patients at risk of adverse postoperative outcomes.

\section{FRAILTY ASSESSMENT TOOLS}

Numerous frailty screening tools have been described over the years ${ }^{[17,18,41]}$. The most commonly implemented one is the "Physical Frailty Phenotype" model by Fried et al ${ }^{[14]}$, which describes frailty as the decrease in physiological reserve secondary to a multisystem functional decline. This tool assesses the following criteria to identify frail patients: (1) walking speed; (2) grip strength; (3) weight loss; (4) physical activity; and (5) exhaustion [Figure 1]. Patients meeting one or two of these criteria are deemed "pre-frail", while those meeting at least three criteria are categorized as frail ${ }^{[14]}$. Makary et al ${ }^{[42]}$ further validated this definition, and at the same time defined as "pre-frail" those fulfilling two or three of the above-mentioned criteria. The Phenotypic frailty tool requires only a questionnaire, a stopwatch, and a dynamometer, and thus can be completed in only 10-15 $\mathrm{min}^{[17]}$. It is also recognized by the American College of Surgeons and the American Geriatric Society for the assessment of the elderly preoperatively ${ }^{[43]}$. Nevertheless, the inherent drawback of this assessment method is the lack of psychosocial evaluation of the older patient ${ }^{[4]]}$.

The second most commonly used frailty assessment tool is the "Deficit Accumulation Index" by Rockwood et al. ${ }^{[15]}$ [Figure 2]. It defines frailty using a frailty index (FI) with the number of deficits or abnormal characteristics accumulated over several areas (i.e., physical, social, functional, and cognitive) on the numerator and the total number of characteristics assessed on the denominator ${ }^{[15,45,46]}$. Higher index values have been associated with an increased likelihood of frailty, adverse patient outcomes, disability, hospitalization, and death ${ }^{[45]}$. Although it is considered more sensitive than the Phenotypic frailty tool ${ }^{[16]}$, its downsides include the fact that it is time-consuming (up to 70 characteristics assessed sometimes) and its extensive focus on comorbidities (symptoms, diagnoses, abnormal values on laboratory tests, etc.) rather than on functional decline ${ }^{[18]}$. With the aim to assess frailty in a timely fashion and in a more efficient way, several modified FIs (mFIs), which may measure as few as five factors, have been generated ${ }^{[47]}$. In fact, 11-point $\mathrm{mFIs}$ have already been used to evaluate patients undergoing liver resection ${ }^{[48,49]}$.

Comprehensive geriatric assessment (CGA) is another well-established approach implemented to evaluate frailty in older patients ${ }^{[0,51]}$. It utilizes assessment tools and laboratory values to assess patients from several 


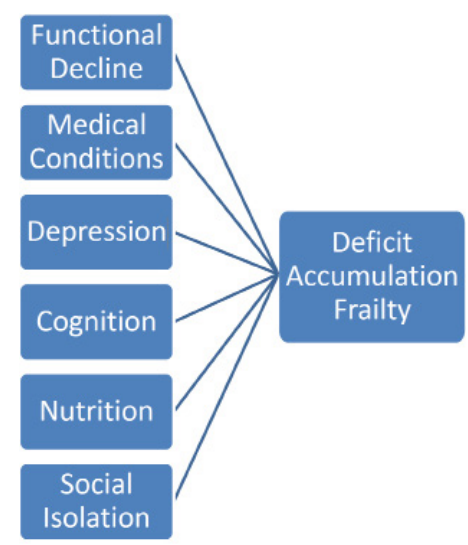

Figure 2. "Deficit Accumulation Index" by Rockwood et al. ${ }^{[15]}$

standpoints, including physical medical comorbidities, nutritional status, mental and cognitive status, physical functioning and fitness, social networking, and environmental status ${ }^{[50,51]}$. A downside that CGA shares with FI is that it is time-consuming, mostly due to its complexity ${ }^{[51]}$. Two screening tools that can help identify elderly patients who will benefit from a more comprehensive assessment with the CGA are the Geriatric-8 (G8) and the Vulnerable Elders Survey-13 (VES-13 ${ }^{[52]}$. Those take into consideration age, self-rated health, and physical function along with other factors ${ }^{[53]}$, and both of them take only 5 min to complete $^{[52]}$. The first one is specifically designed to identify vulnerable older patients with cancer, while the latter is designed to detect vulnerable older patients in the community. Hence, G8 was found to be predictive of postoperative complications in elderly patients with HCC, while VES-13 was not shown to have a predictive role ${ }^{[53]}$. The abbreviated CGA is another screening tool for elderly cancer patients that incorporates only the 15 most important items of the full assessment tool and requires only 5 min to complete $^{[54,55]}$.

The FRAIL (Fatigue, Resistance, Ambulation, Illness, and weight Loss) index is another easy to complete screening tool that deems patients frail if three or more of its components are present ${ }^{[56]}$. A great advantage of this scale is that it has been validated not only in the elderly but also in middle-aged individuals ${ }^{[56,57]}$. On the other hand, the Edmonton Frail Scale (EFS) assesses the patients' health over ten frailty domains (including cognition, general health status, mood, continence, functional performance and independence, social support, polypharmacy, and nutrition $)^{[58]}$. A score below 5 indicates the "no frailty" patients, a score between 6 and 11 identifies the "apparently vulnerable" individuals, and a score between 12 and 17 distinguishes the "severe frailty" patients ${ }^{[59]}$. Studies have shown that EFS is a valid and accurate tool that can be efficiently administered by non-geriatricians to assess and preoperatively optimize geriatric patients with or without cancer ${ }^{[58,60,61]}$. The Clinical Frailty Scale (CFS) is another quick frailty assessment tool based on clinical judgment ${ }^{[62]}$. Data suggest that it can accurately identify patients who may need institutional care, as well as those less likely to survive ${ }^{[62]}$. Data have shown that CFS can reliably distinguish patients who are going to have a complicated course and prolonged LOS while in the acute medical ward ${ }^{[63]}$. A screening tool for frailty broadly used in Japan is the Kihon Checklist $(\mathrm{KCL})^{[64]}$. KCL is a self-reporting "yes/no" survey that can help clinicians assess the status of older individuals in several frailty domains (functional, physical, psychological, and social) ${ }^{[65]}$.

Moreover, there are some single item tools that are less comprehensive but can serve as quick and easy to apply screening tools. The most common tool falling into this category is the handgrip test, which utilizes a hydraulic hand dynamometer to evaluate the maximum strength of the dominant hand ${ }^{[52]}$. Its role in distinguishing "fit" from "frail" older individuals has been validated not only in the general population but also in cancer patients, as handgrip strength is highly associated with survival outcomes ${ }^{[52,66]}$. Although the 
Table 1. Frailty assessment tools

\begin{tabular}{ll}
\hline Tools & Ref. \\
\hline Physical frailty phenotype & {$[14,42]$} \\
Deficit accumulation index & {$[15]$} \\
Comprehensive geriatric assessment & {$[50,51]$} \\
Abbreviated comprehensive geriatric assessment & {$[54,55]$} \\
Geriatric-8 & {$[52,53]$} \\
Vulnerable elders survey-13 & {$[52,53]$} \\
FRAlL index & {$[56]$} \\
Edmonton frail scale & {$[58,59]$} \\
Clinical frailty scale & {$[62]$} \\
Kihon checklist & {$[64,65]$} \\
The handgrip test & {$[52]$} \\
The "Up \& Go" test & {$[52,67]$} \\
\hline
\end{tabular}

FRAIL: fatigue, resistance, ambulation, illness, and weight loss

handgrip test can be applied in multiple settings, another tool particularly useful for hospitalized patients is the timed "Up \& Go" test ${ }^{[67]}$. This test requires the patient to stand up and walk three meters, then to turn, walk back and sit down and can accurately assess balance and functional mobility ${ }^{[52]}$. Data suggest that it is particularly useful in identifying cancer patients at risk of postoperative complications ${ }^{[68]}$. A comprehensive list of the various tools used for the assessment of frailty is shown in Table 1.

\section{LIVER RESECTION AND FRAILTY}

There is a growing body of evidence that frailty assessment tools are useful in identifying frail patients at higher risk of postoperative morbidity and mortality, as well as extended LOS in the hospital. In fact, Kaibori et al. ${ }^{[53]}$ evaluated the utilization of the G8 CGA tool in patients $\geq 70$ years undergoing liver resection for HCC. Patients with a score lower than 14 demonstrated higher postoperative morbidity rate and extended LOS, but no difference in mortality when compared to patients with scores $\geq 14^{[53]}$. Notably, on multivariate analysis, G8 score $<14$ was significantly associated with postoperative morbidity, while age $\geq 77$ years was not found to be a significant risk factor ${ }^{[53]}$. It is worth mentioning that patients with HCC arising on a background of cirrhosis demonstrated a tendency towards inferior outcomes after liver resection ${ }^{[53]}$; however, further research is warranted in order to deduce meaningful conclusions.

Louwers et al. ${ }^{[48]}$ investigated the impact of frailty, assessed by the 11-point mFI tool, on morbidity and mortality after open hepatectomy in 10,300 patients from the National Surgical Quality Improvement Project (NSQIP) database. As the mFI score increased, a statistically significant increase was associated with Clavien 4 complications, mortality, and extended LOS. Notably, this statistical significance was maintained in all types of hepatectomy (partial, right, left, and extended). Although this study highlighted the importance of $\mathrm{mFI}$ in preoperative planning and risk stratification, the authors stressed the need for simpler hepatectomy-specific frailty assessment tools ${ }^{[48]}$. Another study utilizing NSQIP hepatectomy data described the revised FI (rFI) on a "training set" of patients and compared it with the 11-point mFI ("validation set") ${ }^{[49]}$. rFI incorporates several variables, such as preoperative serum albumin and hematocrit, American Society of Anesthesiologists score, BMI, the extent of liver resection, and underlying pathology. Higher rFI scores were significantly associated with postoperative complications, prolonged LOS, and mortality, while higher mFI scores were linked only to a higher risk of morbidity but neither mortality nor $\operatorname{LOS}^{[49]}$. Chen et al. ${ }^{[69]}$ evaluated the use of a five-item $\mathrm{mFI}$ to assess the effect of frailty on outcomes in patients undergoing combined colorectal and liver resection for colorectal cancer and liver metastases. Patients with higher mFI scores exhibited a higher incidence of mortality, overall and severe morbidity, as well as prolonged LOS. On multivariate analysis, higher mFI scores were found to be independent risk factors for overall and severe morbidity, while age was not found to be a significant factor that affects morbidity. 


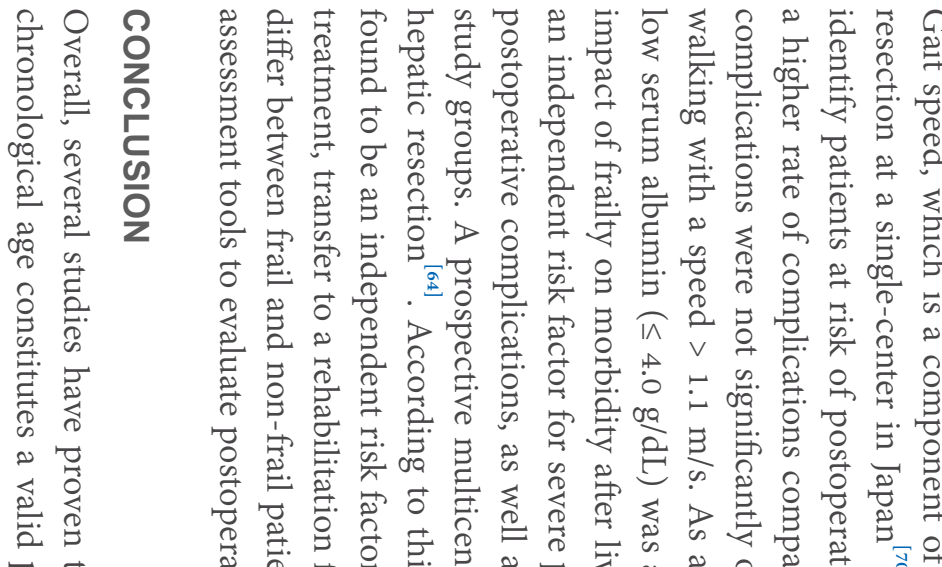

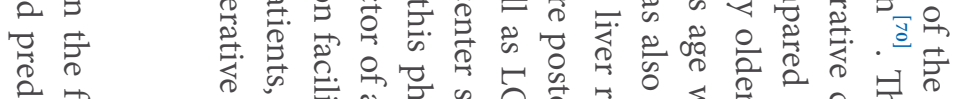

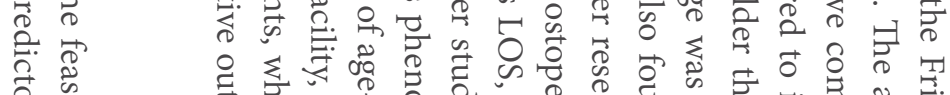

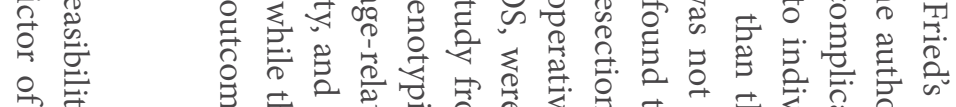

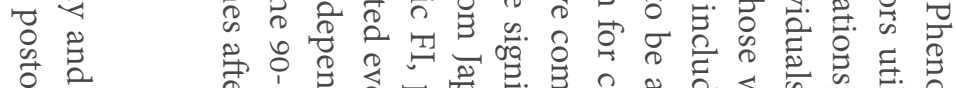

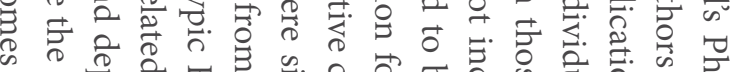

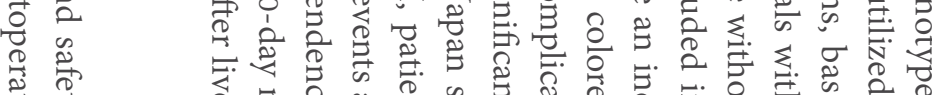

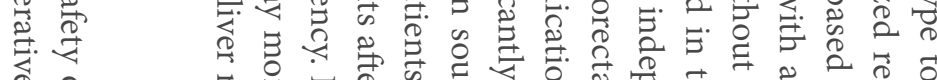

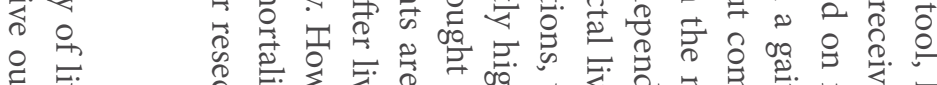

है

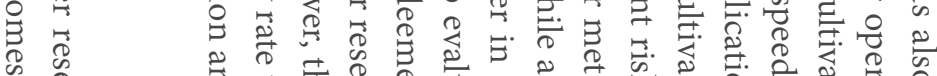

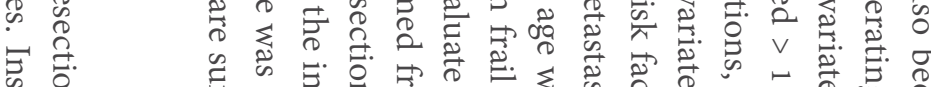

की

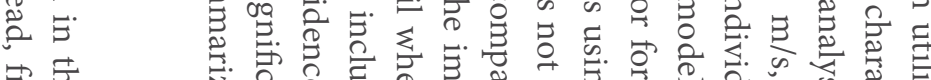

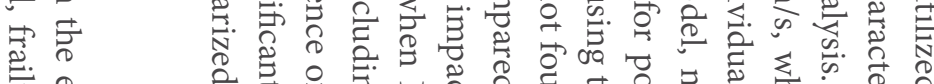

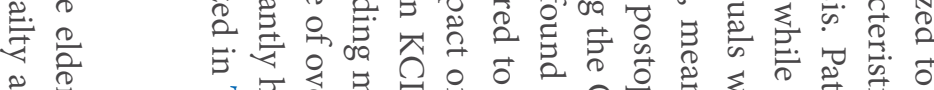

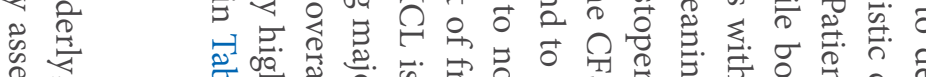

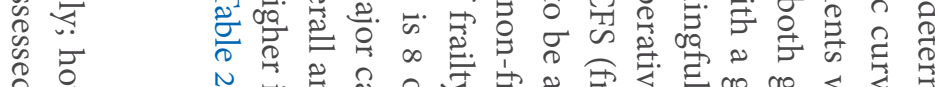

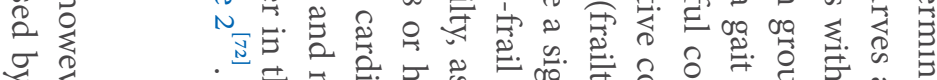

政

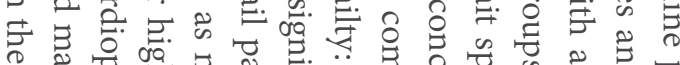

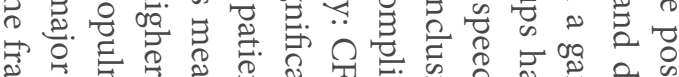

䓪

㻤.

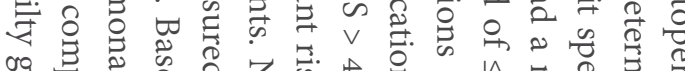

के مे

용

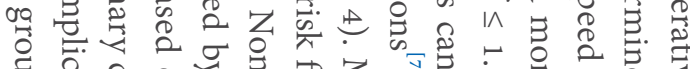

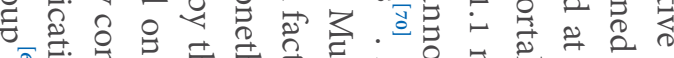

is

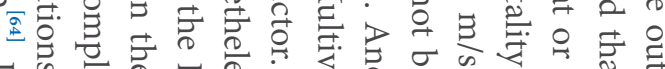

$\forall$ w

空

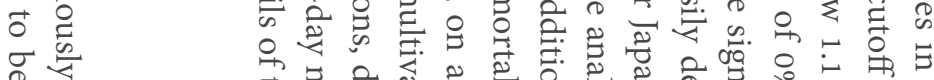

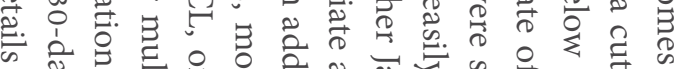

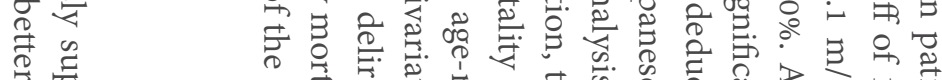

एक

궁

'ซ

옹

웅

苨.

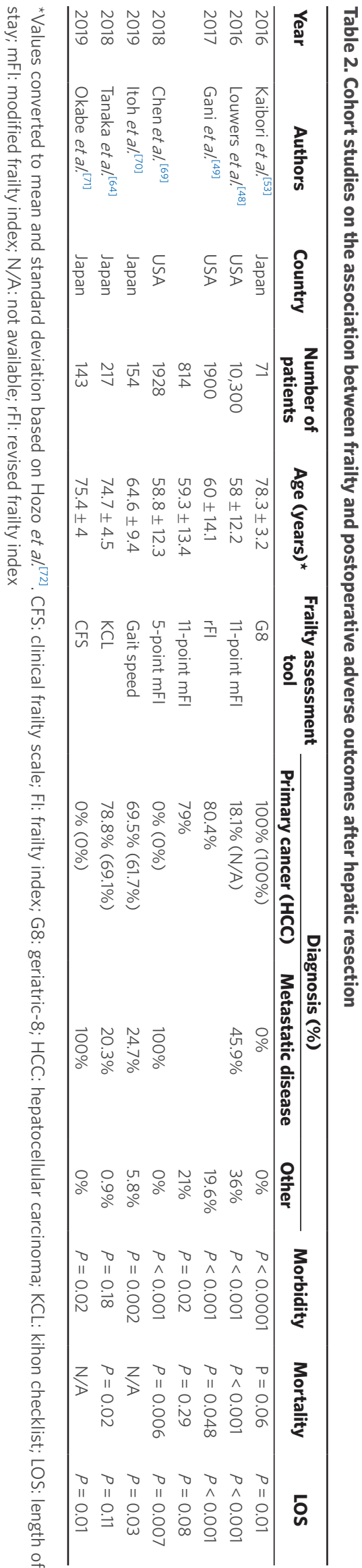


morbidity, mortality, and LOS after liver resection. However, deducing meaningful conclusions remains challenging due to the lack of consensus regarding frailty definition, assessment tools, and score cutoffs. Future studies should focus on performing between-tool comparisons, developing a hepatectomyspecific frailty assessment tool, and evaluating the role of frailty assessment tools in preoperative patient optimization.

\section{DECLARATIONS}

\section{Authors' contributions}

Study concept, data analysis and interpretation, critical revision of the manuscript, final approval of the manuscript: Ziogas IA, Sioutas GS, Tsoulfas G

Data acquisition, drafting of the manuscript: Sioutas GS, Ziogas IA

\section{Availability of data and materials}

Not applicable.

\section{Financial support and sponsorship}

None.

\section{Conflicts of interest}

All authors declared that there are no conflicts of interest.

\section{Ethical approval and consent to participate}

Not applicable.

\section{Consent for publication}

Not applicable.

\section{Copyright}

(c) The Author(s) 2020.

\section{REFERENCES}

1. Tsukioka G, Kakizaki S, Sohara N, Sato K, Takagi H, et al. Hepatocellular carcinoma in extremely elderly patients: an analysis of clinical characteristics, prognosis and patient survival. World J Gastroenterol 2006;12:48-53.

2. Cho SW, Steel J, Tsung A, Marsh JW, Geller DA, et al. Safety of liver resection in the elderly: how important is age? Ann Surg Oncol 2011;18:1088-95.

3. Nanashima A, Abo T, Nonaka T, Fukuoka H, Hidaka S, et al. Prognosis of patients with hepatocellular carcinoma after hepatic resection: are elderly patients suitable for surgery? J Surg Oncol 2011;104:284-91.

4. Shirabe K, Kajiyama K, Harimoto N, Gion T, Tsujita E, et al. Early outcome following hepatic resection in patients older than 80 years of age. World J Surg 2009;33:1927-32.

5. Oishi K, Itamoto T, Kobayashi T, Oshita A, Amano H, et al. Hepatectomy for hepatocellular carcinoma in elderly patients aged 75 years or more. J Gastrointest Surg 2009;13:695-701.

6. Huang J, Li BK, Chen GH, Li JQ, Zhang YQ, et al. Long-term outcomes and prognostic factors of elderly patients with hepatocellular carcinoma undergoing hepatectomy. J Gastrointest Surg 2009;13:1627-35.

7. Lee CW, Chan KM, Tsai HI, Hsieh YC, Lin CY, et al. Hepatic resection for hepatocellular carcinoma in the octogenarian: is it justified? Aging (Albany NY) 2019;11:1537-50.

8. Wu FH, Shen CH, Luo SC, Hwang JI, Chao WS, et al. Liver resection for hepatocellular carcinoma in oldest old patients. World J Surg Oncol 2019;17:1.

9. Oishi K, Itamoto T, Kohashi T, Matsugu Y, Nakahara H, et al. Safety of hepatectomy for elderly patients with hepatocellular carcinoma. World J Gastroenterol 2014;20:15028-36.

10. Jansen PLM. Liver disease in the elderly. Best Pract Res Clin Gastroenterol 2002;16:149-58.

11. Michalopoulos GK. Liver regeneration. J Cell Physiol 2007;213:286-300.

12. Timchenko NA. Aging and liver regeneration. Trends Endocrinol Metab 2009;20:171-6.

13. Taki-Eldin A, Zhou L, Xie HY, Zheng SS. Liver regeneration after liver transplantation. Eur Surg Res 2012;48:139-53.

14. Fried LP, Tangen CM, Walston J, Newman AB, Hirsch C, et al. Frailty in older adults: evidence for a phenotype. J Gerontol A Biol Sci 
Med Sci 2001;56:M146-56.

15. Rockwood K, Howlett SE, MacKnight C, Beattie BL, Bergman H, et al. Prevalence, attributes, and outcomes of fitness and frailty in community-dwelling older adults: report from the Canadian study of health and aging. J Gerontol A Biol Sci Med Sci 2004;59:1310-7.

16. Chen X, Mao G, Leng SX. Frailty syndrome: an overview. Clin Interv Aging 2014;9:433-41.

17. Robinson TN, Walston JD, Brummel NE, Deiner S, Brown CH, et al. Frailty for surgeons: review of a national institute on aging conference on frailty for specialists. J Am Coll Surg 2015;221:1083-92.

18. Richards SJG, Frizelle FA, Geddes JA, Eglinton TW, Hampton MB. Frailty in surgical patients. Int J Colorectal Dis 2018;33:1657-66.

19. Feinstein AR. The pre-therapeutic classification of co-morbidity in chronic disease. J Chronic Dis 1970;23:455-68.

20. Francis L, Silvers A. Perspectives on the Meaning of "Disability". AMA J Ethics 2016;18:1025-33.

21. Beggs T, Sepehri A, Szwajcer A, Tangri N, Arora RC. Frailty and perioperative outcomes: a narrative review. Can J Anaesth 2015;62:143-57.

22. Fulop T, Larbi A, Witkowski JM, McElhaney J, Loeb M, et al. Aging, frailty and age-related diseases. Biogerontology 2010;11:547-63.

23. Clegg A, Young J, Iliffe S, Rikkert MO, Rockwood K. Frailty in elderly people. Lancet 2013;381:752-62.

24. Walston J. Frailty--the search for underlying causes. Sci Aging Knowledge Environ 2004;2004:pe4.

25. Ko FC. Preoperative frailty evaluation: a promising risk-stratification tool in older adults undergoing general surgery. Clin Ther 2019;41:387-99

26. Fong Y, Cohen AM, Fortner JG, Enker WE, Turnbull AD, et al. Liver resection for colorectal metastases. J Clin Oncol 1997;15:938-46.

27. Ferrero A, Viganò L, Polastri R, Ribero D, Tesoriere R Lo, et al. Hepatectomy as treatment of choice for hepatocellular carcinoma in elderly cirrhotic patients. World J Surg 2005;29:1101-5.

28. Ijtsma AJC, Boevé LMS, van der Hilst CS, de Boer MT, de Jong KP, et al. The survival paradox of elderly patients after major liver resections. J Gastrointest Surg 2008;12:2196.

29. Adam R, Frilling A, Elias D, Laurent C, Ramos E, et al. Liver resection of colorectal metastases in elderly patients. Br J Surg 2010;97:366-76.

30. Sulpice L, Rayar M, Campillo B, Pery C, Guillaud A, et al. Advanced age remains an achilles heel for liver resections. World J Surg 2014;38:918-26.

31. Reddy SK, Barbas AS, Turley RS, Gamblin TC, Geller DA, et al. Major liver resection in elderly patients: a multi-institutional analysis. J Am Coll Surg 2011;212:787-95.

32. Ziogas IA, Tsoulfas G. Evolving role of Sorafenib in the management of hepatocellular carcinoma. World J Clin Oncol 2017;8:203-13

33. Brunot A, Le Sourd S, Pracht M, Edeline J. Hepatocellular carcinoma in elderly patients: challenges and solutions. J Hepatocell Carcinoma 2016;3:9-18

34. Ziogas IA, Tsoulfas G. Advances and challenges in laparoscopic surgery in the management of hepatocellular carcinoma. World J Gastrointest Surg 2017;9:233-45.

35. Giovanardi F, Lai Q, Bertacco A, Vitale A. Resection for hepatocellular cancer: overpassing old barriers. Transl Gastroenterol Hepatol 2018;3:64.

36. Kondo K, Chijiiwa K, Funagayama M, Kai M, Otani K, et al. Hepatic resection is justified for elderly patients with hepatocellular carcinoma. World J Surg 2008;32:2223-9.

37. Hamaoka M, Kobayashi T, Ishiyama K, Ohira M, Tahara H, et al. Evaluation of the risk factors and prognostic factors of hepatectomy for hepatocellular carcinoma in patients aged 80 years or more. J Hepatobiliary Pancreat Sci 2017;24:58-64.

38. Portolani N, Baiocchi GL, Coniglio A, Tiberio GAM, Prestini K, et al. Limited liver resection: a good indication for the treatment of hepatocellular carcinoma in elderly patients. Jpn J Clin Oncol 2011;41:1358-65.

39. Mizuguchi T, Kawamoto M, Meguro M, Okita K, Ota S, et al. Impact of aging on morbidity and mortality after liver resection: a systematic review and meta-analysis. Surg Today 2015;45:259-70.

40. Phan K, An VVG, Ha H, Phan S, Lam V, et al. Hepatic resection for malignant liver tumours in the elderly: a systematic review and meta-analysis. ANZ J Surg 2015;85:815-22.

41. Dent E, Kowal P, Hoogendijk EO. Frailty measurement in research and clinical practice: a review. Eur J Intern Med 2016;31:3-10.

42. Makary MA, Segev DL, Pronovost PJ, Syin D, Bandeen-Roche K, et al. Frailty as a predictor of surgical outcomes in older patients. J Am Coll Surg 2010;210:901-8

43. Chow WB, Rosenthal RA, Merkow RP, Ko CY, Esnaola NF. Optimal preoperative assessment of the geriatric surgical patient: a best practices guideline from the American College of Surgeons National Surgical Quality Improvement Program and the American Geriatrics Society. J Am Coll Surg 2012;215:453-66.

44. Hubbard R, Ng K. Australian and New Zealand Society for Geriatric Medicine: position statement - frailty in older people. Australas J Ageing 2015;34:68-73.

45. Rockwood K, Mitnitski A. Frailty in relation to the accumulation of deficits. J Gerontol A Biol Sci Med Sci 2007;62:722-7.

46. Rockwood K, Stolee P, McDowell I. Factors associated with institutionalization of older people in Canada: testing a multifactorial definition of frailty. J Am Geriatr Soc 1996;44:578-82.

47. Subramaniam S, Aalberg JJ, Soriano RP, Divino CM. New 5-factor modified frailty index using American College of Surgeons NSQIP Data. J Am Coll Surg 2018;226:173-81.e8.

48. Louwers L, Schnickel G, Rubinfeld I. Use of a simplified frailty index to predict Clavien 4 complications and mortality after hepatectomy: analysis of the National Surgical Quality Improvement Project database. Am J Surg 2016;211:1071-6.

49. Gani F, Cerullo M, Amini N, Buettner S, Margonis GA, et al. Frailty as a risk predictor of morbidity and mortality following liver surgery. J Gastrointest Surg 2017;21:822-30.

50. Welsh TJ, Gordon AL, Gladman JR. Comprehensive geriatric assessment--a guide for the non-specialist. Int J Clin Pract 2014;68:290-3.

51. Feng MA, McMillan DT, Crowell K, Muss H, Nielsen ME, et al. Geriatric assessment in surgical oncology: a systematic review. J 
Surg Res 2015;193:265-72.

52. Decoster L, Van Puyvelde K, Mohile S, Wedding U, Basso U, et al. Screening tools for multidimensional health problems warranting a geriatric assessment in older cancer patients: An update on SIOG recommendations. Ann Oncol 2015;26:288-300.

53. Kaibori M, Ishizaki M, Matsui K, Iida H, Inoue K, et al. Geriatric assessment as a predictor of postoperative complications in elderly patients with hepatocellular carcinoma. Langenbeck's Arch Surg 2016;401:205-14.

54. Overcash JA, Beckstead J, Extermann M, Cobb S. The abbreviated comprehensive geriatric assessment (aCGA): a retrospective analysis. Crit Rev Oncol Hematol 2005;54:129-36.

55. Overcash JA, Beckstead J, Moody L, Extermann M, Cobb S. The abbreviated comprehensive geriatric assessment (aCGA) for use in the older cancer patient as a prescreen: scoring and interpretation. Crit Rev Oncol Hematol 2006;59:205-10.

56. Morley JE, Malmstrom TK, Miller DK. A simple frailty questionnaire (FRAIL) predicts outcomes in middle aged African Americans. J Nutr Health Aging 2012;16:601-8.

57. Woo J, Yu R, Wong M, Yeung F, Wong M, Lum C. Frailty screening in the community using the FRAIL scale. J Am Med Dir Assoc 2015;16:412-9.

58. Rolfson DB, Majumdar SR, Tsuyuki RT, Tahir A, Rockwood K. Validity and reliability of the Edmonton Frail Scale. Age Ageing 2006;35:526-9.

59. Perna S, Francis MD, Bologna C, Moncaglieri F, Riva A, et al. Performance of edmonton frail scale on frailty assessment: its association with multi-dimensional geriatric conditions assessed with specific screening tools. BMC Geriatr 2017;17:2.

60. Meyers BM, Al-Shamsi HO, Rask S, Yelamanchili R, Phillips CM, et al. Utility of the edmonton frail scale in identifying frail elderly patients during treatment of colorectal cancer. J Gastrointest Oncol 2017;8:32-8.

61. Partridge JSL, Harari D, Dhesi JK. Frailty in the older surgical patient: a review. Age Ageing 2012;41:142-7.

62. Rockwood K, Song X, MacKnight C, Bergman H, Hogan DB, et al. A global clinical measure of fitness and frailty in elderly people. CMAJ 2005;173:489-95.

63. Juma S, Taabazuing MM, Montero-Odasso M. Clinical frailty scale in an acute medicine unit: a simple tool that predicts length of stay. Can Geriatr J 2016;19:34-9.

64. Tanaka S, Ueno M, Iida H, Kaibori M, Nomi T, et al. Preoperative assessment of frailty predicts age-related events after hepatic resection: a prospective multicenter study. J Hepatobiliary Pancreat Sci 2018;25:377-87.

65. Satake S, Senda K, Hong YJ, Miura H, Endo H, et al. Validity of the kihon checklist for assessing frailty status. Geriatr Gerontol Int 2016;16:709-15

66. García-Peña C, García-Fabela LC, Gutiérrez-Robledo LM, García-González JJ, Arango-Lopera VE, Pérez-Zepeda MU. Handgrip strength predicts functional decline at discharge in hospitalized male elderly: a hospital cohort study. PLoS One 2013;8:e69849.

67. Podsiadlo D, Richardson S. The timed "Up \& Go": a test of basic functional mobility for frail elderly persons. J Am Geriatr Soc 1991;39:142-8.

68. Huisman MG, van Leeuwen BL, Ugolini G, Montroni I, Spiliotis J, et al. "Timed Up \& Go": a screening tool for predicting 30-day morbidity in onco-geriatric surgical patients? A multicenter cohort study. PLoS One 2014;9:e86863.

69. Chen SY, Stem M, Cerullo M, Gearhart SL, Safar B, et al. The effect of frailty index on early outcomes after combined colorectal and liver resections. J Gastrointest Surg 2018;22:640-9.

70. Itoh S, Yoshizumi T, Sakata K, Motomura T, Mano Y, et al. Slow gait speed is a risk factor for complications after hepatic resection. J Gastrointest Surg 2019;23:1810-6.

71. Okabe H, Hayashi H, Higashi T, Nitta H, Ikuta Y, et al. Frailty predicts severe postoperative complication after elective hepatic resection. Gastrointest Tumors 2019;6:28-35.

72. Hozo SP, Djulbegovic B, Hozo I. Estimating the mean and variance from the median, range, and the size of a sample. BMC Med Res Methodol 2005;5:13. 